\title{
LA CONSTITUCIÓN DE CÁDIZ Y SU LEGADO SOCIAL Y POLÍTICO EN NUEVA ESPAÑA 1812-1815 ${ }^{1}$
}

\author{
Mario Trujillo Bolio \\ CIESAS/ FCPYS-UNAM
}

\section{RESUMEN}

El propósito del ensayo es reconstruir históricamente como la Constitución de Cádiz se hizo presente en la sociedad novohispana en el terreno de su ordenamiento jurídico y organicidad política. Se hace un recuento sobre el significado que tuvieron los contenidos de la Constitución gaditana para la administración virreinal y en la gestión de las juntas de gobiernos provinciales. Se valora la noción de ciudadanía para los distintos sectores de la sociedad de Nueva España y la sobresaliente gestión de indios, mestizos y españoles en los ayuntamientos que se crearon en distintas intendencias de Nueva España durante el periodo de 1812 y 1815.

PALABRAS CLAVE: Nueva España, diputados novohispanos, juntas provinciales, ayuntamiento, indios, castas, ciudadanía, representación.

1 Una versión reducida de este trabajo, que se intituló "Presencia de la Constitución de Cádiz en la convulsionada sociedad novohispana 1812-1814”, se publicó en Alberto Ramos (ed.): La Constitución de Cádiz y su huella en América, Cádiz, Universidad de Cádiz, 2011. pp. 211-218. En esta ocasión y a partir del contenido de este artículo, lo que se pretende es dejar claramente establecidos y de manera puntual, los planteamientos referidos al verdadero alcance que tuvo el liberalismo gaditano y la Constitución de Cádiz de 1812 en la sociedad novohispana en el periodo de estudio. 


\section{ABSTRACT}

This paper seeks to analyze the Cadiz Constitution and its affects in the New Spain society, especially in the juridical organization and political life. This paper describes about their articles and theirs meanings for the viceroyalty of New Spain and the meeting county council. In this sense, the paper analyzes the notion of citizenship for the several classes in the New Spain: indigenous, mestizos and Spaniards. These groups had an important participation in the town council of the New Spain's intendancies during 1812 and 1815.

KEY WORDS: Members of the Cortes, meeting county council, town council, indigenous, class, citizenship, representation, viceroyalty of New Spain.

Cádiz fue un imposible porque imposible fue el desarrollo de un liberalismo de corte ilustrado, debido al acoso político y a la represión permanente del conservadurismo monárquico, nobiliario y eclesial; un liberalismo acusado continuamente de radical cuando no de jacobino, de antieclesiástico o de antipatriota, y por tanto aplastado desde el púlpito, las comisarías, los tribunales y a veces, los pelotones sumarísimos ${ }^{2}$.

\section{LAS CORTES Y LA CONSTITUCIÓN GADITANA EN EL ESPACIO SOCIAL NOVOHISPANO}

Cinco meses después de que la Constitución política de la Monarquía Española se hizo realidad el 19 de marzo de 1812 en Cádiz, en Nueva España se iniciaron actos protocolarios en donde el tradicional Te Deum estuvo incluido para celebrar el trascendente acontecimiento ${ }^{3}$. Si bien la noticia se conoció en el puerto de Veracruz el 6 de septiembre, el juramento de la Constitución gaditana en territorio novohispano no se hizo realidad hasta el 30 de septiembre del mismo año. Inclusive, no faltó la colocación de un rótulo en el preeminente espacio político de la ciudad de México que así decía: Plaza de la Constitución. Este significativo nombre que en 1812 se plasmó en el hoy llamado zócalo capitalino, todavía es posible leerlo pero ahora en algunos letreros de las calles ubicadas enfrente del edificio del Antiguo Ayuntamiento y en el Palacio Nacional.

A todo esto, cabe preguntarse entonces, qué consecuencia tuvieron en Nueva España y por qué todavía trascienden en el México moderno, las obras e ideas políticas y sociales de la Constitución de Cádiz. Gran parte de las respuestas trataremos

2 MARCHENA, Juan: "La Constitución de Cádiz y su impacto americano. De fracasos y derrotas", en Heraclio Bonilla (ed.): La Constitución de 1812 en Hispanoamérica y España, Bogotá, Editgor, 2012, p. 23.

3 FRASQUET, Ivana: "Cádiz en América: Liberalismo y Constitución”, Mexican Studies/ Estudios Mexicanos, $\mathrm{n}^{\mathrm{o}} 20$ (2006), pp. 31-43. 
de responderlas si hacemos un detenido repaso histórico de los alcances que tuvo la vigencia la Constitución gaditana en los distintos ámbitos sociales y políticos de Nueva España.

Se puede reflexionar el alcance que tuvo la Constitución gaditana en la Nueva España, si nos remitimos al mismo proceso que permitió la misma elaboración del capitulado del constitucional y, después, su misma aplicación en la sociedad novohispana. En los mismos debates que se dieron en las sesiones de las Cortes en Cádiz, resultan interesantes las intervenciones de los diputados novohispanos -José Simeón de Uría, José Miguel Guridi y Alcocer, y Miguel Gordoa- en septiembre de 1811, cuando cuestionaron en el mismo pleno de los diputados, los aspectos relacionados con la ciudadanía que residía realmente en la nación Española y la forma que debería tener la representación de los americanos en las Cortes. Se ha consignado que los diputados novohispanos insistieron en defender la condición del ciudadanato particularmente a las clases marginadas de Nueva España, esto es, que los indios, negros, mestizos y mulatos tuviesen también la misma calidad de ciudadano que los españoles de la Península ${ }^{4}$. Si bien es cierto que los beligerantes diputados novohispanos fracasaron en su intento para que se les diera a las castas el derecho ciudadano en el texto de la Constitución política de la Monarquía Española, hay que decir que en Nueva España para ese entonces, el escenario político se complicó notablemente. En efecto, la sociedad novohispana no estuvo en condiciones para que abiertamente se involucrara en una reforma liberal que buscó los derechos y garantías de los ciudadanos y todo, precisamente, por el levantamiento insurgente que había iniciado el 15 de septiembre de 1810. Mientras en Cádiz los diputados americanos y peninsulares buscaron terminar la redacción de una Constitución liberal y hacerla cumplir en España y sus colonias en América, particularmente en Nueva España la realidad resultó compleja. Sobre este aspecto, Juan Marchena acierta claramente al decirnos que la sociedad novohispana para ese entonces se encontraba abiertamente dividida pues:

“...las élites criollas y peninsulares se encargaban de masacrar sin piedad al gentío indígena-campesino que marchaba tras los estandartes guadalupanos de Hidalgo y Morelos, en procura precisamente de lo que los diputados gaditanos reclamaban con fuerza desde la tribuna; si en Cádiz defender estos derechos parecía posible, en México estas reivindicaciones sonaban a disparates monstruosos".

\section{SOBRE LOS PRECEPTOS CONSTITUCIONALES GADITANOS QUE SÍ RINDIERON FRUTOS}

Pese a la magra situación que se vivía en la sociedad novohispana en los primeros años de la década de 1810, hay que analizar en cambio, algunos hechos interesantes que trascendieron y que, de manera específica, se pueden ubicar en la labor que se des-

4 TRUJILlO BOLIO, Mario: "La presencia de los diputados novohispanos en las Cortes de Cádiz 18101814" en Alberto Gullón y Antonio Gutiérrez (Coord.): La Constitución gaditana de 1812 y sus repercusiones en América, Vol.1. Cádiz, Universidad de Cádiz, 2012, pp.361-364.

5 MARCHENA, Juan: "La Constitución de Cádiz y el ocaso del sistema colonial español en América", en Constitución política de la Monarquía Española. Cádiz, 1812. Sevilla, Fundación El Monte, 2000, p. 104. 
plegó en las Cortes instaladas en Cádiz a partir de la emisión de varios decretos y del cumplimiento del capitulado de la Constitución que, al menos durante los años de 1812 y 1814, incidieron en lo religioso, político, social y económico de Nueva España. En este sentido, resulta interesante el planteamiento de Heraclio Bonilla cuando establece que al menos:

“...la Carta de 1812 en efecto consagra el principio de la soberanía nacional, la caducidad de los privilegios estamentales, la abrogación de las formas más aberrantes de la explotación impuesta a la población nativa, la liquidación de la Inquisición, la libertad de prensa, la convocatoria a elecciones para que las colonias americanas elijan a sus representantes en las cortes, el carácter democrático que en adelante debían tener cabildos y ayuntamientos".

Sin embargo, es necesario señalar cuáles fueron concretamente las transformaciones que realmente desde la Constitución gaditana se pretendían hacer para modificar el antiguo régimen absolutista en España y en sus colonias de ultramar. Lo anterior puede encontrarse de forma muy explícita en el estudio de Manuel Ferrer sobre lo significativo que tuvo la Constitución de Cádiz en el ámbito de la sociedad novohispana, al advertirnos puntualmente que las repercusiones anticlericales se concretaron en: “...expulsión de jesuitas, desamortización de los bienes del clero regular, limitaciones en el número de monasterios y conventos, reducción del diezmo, supresión del fuero eclesiástico para determinados delitos"7. A esto habría que agregarle la extinción del tribunal de la Inquisición el 8 de junio de 1813; y el establecimiento de la libertad de prensa que data desde el 5 de octubre de 1811, aspecto este último que, lamentablemente, en Nueva España tuvo pocos resultados ${ }^{8}$.

Asimismo, hay que señalar que en Nueva España durante los años que van de 1812 a 1814, la gestión pública y la política fiscal de la Real Hacienda que logró desprenderse de lo establecido por las Cortes y la Constitución de Cádiz, trató de aplicarse para fortalecer las precarias finanzas novohispanas. Los ayuntamientos novohispanos dentro de su política interior determinaron diversas ordenanzas municipales e implementaron la ejecución de arbitrios para las obras públicas, obtuvieron ingresos para las rentas municipales y se dispusieron dineros para instrucción pública, policía de salubridad y casas de beneficencia. Las instituciones como la aduana, casa de moneda y de rentas ya no tuvieron la denominación de "reales", sino que se les llamó, en cambio, casas nacionales.

Sin embargo, lo más significativo respecto a la política fiscal en los tres años señalados, es lo que José Antonio Serrano ha indagado respecto a la importancia que alcanzaron los ingresos para la Real Hacienda -no sólo los generados por el estanco del tabaco, las gabelas, o las alcabalas-, sino de aquellos rubros que se desprendieron de la

6 BONILLA, Heraclio: "Presentación” en Heraclio Bonilla (ed.): La Constitución de 1812 en Hispanoamérica y España, Bogotá, Editgor, 2012, p. 13.

7 FERRER MUÑ̃Z, Manuel: Constitución de Cádiz y su aplicación en la Nueva España. Pugna entre el antiguo y nuevo régimen en el virreinato, 1810-1821. México, Instituto de Investigaciones Jurídicas-UNAM, 1993, p. 77.

8 TRUJILLO BOLIO, Mario: "Libertad de expresión e imprenta en Nueva España en el escenario de las Cortes de Cádiz y la guerra de Independencia mexicana (1810-1814)", Revista Iberoamericana de Derechos y Libertades Civiles, Universidad de Cádiz-Universia, no 0 (2010), pp.111-115. 
implementación de contribuciones directas para resarcir la penuria fiscal provocada por el enfrentamiento de las fuerzas insurgentes y realistas.

En consecuencia, tenemos que Francisco Javier Venegas de Saavedra, con funciones de Virrey/Jefe Superior, después de emitir un bando en febrero de 1812, logró significativas contribuciones directas por el impuesto de fincas del cinco por ciento, y fuese ello por el arrendamiento de bienes inmuebles, o bien por aquel impuesto que cubrirían los inquilinos con el mismo monto y que se conoció como "pensión de casas" o "contribución de inquilinatos". Inclusive, la propia racionalización administrativa -que abarcó ciudades, villas y pueblos- para obtener contribuciones de los inquilinatos, fue el levantamiento de padrones en distintas intendencias en fincas y poblaciones como la ciudad de México, Zacatecas, Mérida, y San Luis Potosí. Hay que subrayar que lo anterior le permitió inclusive al virrey Venegas, que bajo el ordenamiento de la Constitución de Cádiz se multiplicaran juntas recaudatorias más eficaces en plena guerra de Independencia ${ }^{9}$.

En el entorno de las estructuras de dominación y aparatos del Estado imperial español, con la Constitución de Cádiz se pretendieron cambios que necesariamente quebrantaban el despotismo absolutista en España y también en las posesiones de ultramar como fue el caso de Nueva España. Para ello se establecieron juntas electorales, se nombraron diputados a cortes -como se dispuso en el Título III. De las Cortes, capítulos: II. Del nombramiento de diputados de Córtes, III. De las juntas electorales de parroquia, IV. De las Juntas electorales de partido, y V. De las Juntas electorales de provincia-; y se organizaron sufragios para conformar ayuntamientos, como se advierte en el Título VI. Del gobierno interior de las provincias y de los pueblos, capítulos I De los Ayuntamientos y II Del gobierno político de las provincias, y de las diputaciones provinciales ${ }^{10}$.

Al mismo tiempo, el documento constitucional pretendió renovadas formas de gobierno a través de juntas provinciales ${ }^{11}$. Con ello, en el extenso y pródigo reino de Nueva España se pretendía sustituir a la figura del virrey, que tenía considerables atribuciones en el poder político. No obstante, con los dictados constitucionales el poder ejecutivo sería ejercido por un "Jefe Superior" o "Jefe Político". Dicha modificación política parecía sustancial debido a que el Jefe Superior no tendría aquella audiencia que le servía servilmente como consejera a partir de sus tradicionales funciones jurídicas especiales -para obras públicas, mayorazgos, de policía y de repúblicas de los indios-, dado que a esta instancia se le sustituyó por un tribunal superior ordinario.

\section{CREACIÓN DE LA CIUDADANÍA Y PARTICIPACIÓN POLÍTICA EN LOS AYUNTAMIENTOS}

Sin duda, las modificaciones que nos parecen más trascendentes de la Constitución de Cádiz son las que sobresalieron en la labor política de los ayuntamientos novohispa-

\footnotetext{
9 SERRANO, José Antonio: Igualdad, uniformidad, proporcionalidad. Contribuciones directas y reformas fiscales en México 1810-1846. México, El Colegio de Michoacán-Instituto Mora, México, 2007, pp. 26-30. 10 Véase al respecto: Constitución política de la Monarquía Española.

11 Las Cortes habían determinado para fines militares y comandados por capitanes generales dividir el reino de la Nueva España y sus Provincias Internas en siete distritos con sus provincias con sus diputaciones provinciales y jefes políticos: Nueva Galicia, San Luis Potosí, Provincias Internas de Oriente, Provincias Internas de Occidente, Yucatán y Guatemala. En tanto que para Nueva España se dividía en nueve provincias: México, Puebla, Michoacán, Guanajuato, Oaxaca, Veracruz, San Luis Potosí, Tlaxcala y Querétaro.
} 
nos. Estos, con el nuevo ordenamiento constitucional, no los ocuparían ya los regidores perpetuos, sino ciudadanos elegidos en una elección popular. Esto no fue casual debido a que se plasmó precisamente en la Constitución de Cádiz en su Título VI artículo 310 que a la letra dice: "Se pondrán ayuntamientos en los pueblos que no le tengan y en que convengan le haya, no pudiendo dejar de haberle en los que por sí o en su comarca lleguen a mil almas...".

Así, los alcaldes -mejor conocidos como "cadañeros"-, estarían en funciones por doce meses y su reelección podría realizarse sólo hasta dos años después de haber asumido el cargo. El renovado ayuntamiento que se desprendió de la legislación liberal gaditana, lo constituirían uno o dos alcaldes según el porcentaje poblacional de las provincias, los regidores y un procurador síndico. Con todo, los cargos de elección popular ya podían ser asumidos además de por peninsulares, por indios, criollos y mestizos. Sobre esto, hay un balance sustantivo pues como bien dice Antonio Serrano:

“...el establecimiento de la Constitución de gaditana en marzo de 1812 provocó que en el virreinato de Nueva España se multiplicara el número de ayuntamientos. Se ha calculado que en esos años se fundaron más de 800 , mismos que se sumaron a los 30 que ya funcionaban antes de $1808^{\prime \prime}$.

Cabe decir también, que esta forma de gobierno liberal mermaba el poderío corporativo de las élites hereditarias que, ocasionalmente, controlaban la autoritaria y costosa burocracia peninsular virreinal ${ }^{13}$.

En la historiografía mexicana se cuenta con varios análisis que han reconstruido la conformación de distintos cuerpos políticos emanados de la legislación gaditana. Algunos analizan la formación de las llamadas "Juntas Generales" en Puebla, Orizaba, San Miguel el Grande, Mérida, ciudad de México y Querétaro ${ }^{14}$. Por otro lado, sobresalen ensayos referidos a la elección de diputados novohispanos a Cortes ${ }^{15}$ y existen abundantes monografías históricas referidas a la conformación de ayuntamientos constitucionales en distintas provincias novohispanas ${ }^{16}$. Dichos aportes demuestran que en los procesos de elección de cabildos constitucionales fueron elegidos no tan sólo por corporaciones de criollos y peninsulares en las principales villas y ciudades como Puebla, Mérida, Guadalajara, San Luis Potosí, Veracruz y México ${ }^{17}$, sino que también pudieron crearse ayuntamientos en el espacio rural novohispano. En efecto, se tienen contribuciones que indagan como en poblaciones con un alto porcentaje de indios y mestizos tuvieron el derecho del sufragio y de ser elegidos, tal y como se ha constatado en Aguascalientes ${ }^{18}$, además de otros importantes pueblos de indios como Pátzcuaro,

12 SERRANO, José Antonio: op. cit.,p. 32.

13 RODRIGUEZ, Jaime, "De súbditos de la Corona a ciudadanos republicanos: el papel de los autonomistas en la Independencia de México," en Josefina Vázquez (Coord.): Interpretaciones de la Independencia, México, Nueva Imagen, 1977, pp. 55-57.

14 ROJAS Beatriz: 2008. "Las ciudades novohispanas ante la crisis: entre la antigua y la nueva constitución, 1808-1814", Historia Mexicana, vol. LVIII, nº 1 (julio-sep, 2008), pp. 287-324.

15 TRUJILLO BOLIO, Mario: "La presencia de los diputados novohispanos...".

16 ANNINO, Antonio: "Cádiz y la revolución territorial de los pueblos mexicanos, 1812-1821", en Antonio Annino (ed.): Historia de las elecciones en Iberoamérica, siglo XIX, México, FCE, 1995, pp. 177-226.

17 Véanse los distintos trabajos en GUZMÁN PÉREZ, Moisés (coord.): Cabildos, Repúblicas y Ayuntamientos Constitucionales en la Independencia de México, Michoacán, 2009.

18 ROJAS, Beatriz, Las instituciones de gobierno y la élite local. Michoacán, 1998. 
Valladolid, Zitácuaro, Urupan y Oaxaca, y en sitios con poblaciones mineras en donde, por cierto, destacó Guanajuato ${ }^{19}$.

Si bien para el periodo de estudio los indios aún no tenían claramente diferenciado el carácter proporcional de los ciudadanos para ser elegidos en determinados cargos que se establecía en las leyes de la Constitución de Cádiz, este sector mayoritario en la sociedad novohispana sí hizo explícito su derecho de elegir popularmente a sus autoridades. En los llamados Cabildos de indios no tan sólo se tenía el referente de elegir a sus representantes, sino que persistía culturalmente el referente precolombino en donde ejercían la representación natural de sus pueblos de acuerdo a prácticas distintas que no tenían que ver con la imposición jurídica y derecho español. Mientras los españoles buscaron el control político en sus Cabildos y garantizar sus intereses económicos, los indios ya como ciudadanos fueron activos partícipes para que un ayuntamiento con mayor población indígena estuviese bajo su tutela para controlar el usufructo de las tierras y aguas de sus comunidades.

A este respecto, recientemente se ha reconstruido la participación ciudadana de los indios bajo los dictados de la Constitución gaditana. La historiadora Claudia Guarisco advierte, al estudiar los ayuntamientos del Valle de México, que los indios de esta región tuvieron a bien participar en las Juntas provinciales para pactar en las poblaciones indígenas el poder local. En este sentido, Guarisco advierte que cien ayuntamientos fueron creados en las distintas parroquias de la jurisdicción del Valle de México y con tranquilos procesos electorales. Enfatiza que todavía mestizos y españoles cubrieron la función de alcaldes y que, en cambio, los indígenas tan sólo ocuparon cargos de regidores. Sin embargo, esta autora subraya que ya con el ordenamiento constitucional gaditano se dio una hibridación institucional constituida por españoles, mestizos e indígenas, y todo a partir de un explícito convenio entre los distintos estamentos de la sociedad novohispana y muestra, claramente, como es que se dio la negociación política en la elección de ayuntamientos:

Con el fin de alcanzar sus objetivos, los indios dieron sus votos a los vecinos mestizos y españoles de bajo rango, de manera que pudieran ocupar las posiciones de alcaldes y síndicos. A cambio, estos últimos se comprometieron a respetar la vieja organización política indígena. El compromiso comportó, asimismo, que los viejos gobernadores indígenas de cada pueblo fueran elegidos como regidores, encargados de vigilar el cumplimiento de la promesa de respeto a la diversidad, y de canalizar la cooperación indígena en los asuntos locales ${ }^{20}$.

\section{EL DESENLACE DE UNA ROMERÍA CONSTITUCIONAL}

Desde fines del mes de noviembre de 1812, se abrió el proceso para la elección del importante ayuntamiento de la ciudad de México, en donde sólo estuvieron propuestos

19 Nos remitimos al interesante trabajo de SERRANO ORTEGA, José Antonio: "Ciudadanos naturales. Pueblos de indios y ayuntamientos en Guanajuato", en Juan Ortiz y José Antonio Serrano (eds.): Ayuntamiento y liberalismo gaditano en México, Michoacán, El Colegio de Michoacán-Universidad Veracruzana, 2007, pp. 411-440.

20 GUARISCO, Claudia: "La constitución de Cádiz de 1812 y los indios de Lima y el Valle de México: Ayuntamientos, tradición y representación” en Heraclio Bonilla (ed.): La Constitución de 1812 en Hispanoamérica y España, Bogotá, Universidad Nacional de Colombia y Alcaldía Mayor de Bogotá, 2012, pp. 218-224. 
como candidatos peninsulares y criollos. Juan Marchena advierte que solamente fueron votados criollos y comenta las complicaciones que tuvo la jornada comicial: "Fueron tremendamente complicadas: votó mucha gente que no estaba en las listas, en los barrios votaron las castas (que como sabemos no podían hacerlo)..."21. En efecto, la historia registra que hubo un marcado incumplimiento del resultado que tuvieron los comicios precisamente en la capital del virreinato de la Nueva España. Esto se debió a la parálisis política que implementó Francisco Javier Venegas que fungía para ese entonces como Virrey/Jefe Superior de Nueva España. La suspensión la hizo bajo el argumento de que las elecciones se habían realizado irregularmente y por haberse escenificado los días 29 y 30 de noviembre distintos movimientos populares que cuestionaban al inestable régimen monárquico en Nueva España y en donde los protagonistas lanzaron consignas muy ilustrativas del momento que se vivía para esa fecha: ¡Vivan los insurgentes!, ¡Viva Morelos!, ¡Mueran los gachupines!, ¡Vivan los criollos!, ¡Muera el gobierno!

Al mismo tiempo, la actitud de Venegas por frustrar las disposiciones constitucionales la justificó por sobresalir, en ese tiempo, un contexto político delicado para Nueva España como consecuencia de la guerra de independencia que aún se hacía sentir con la beligerancia del ejército insurrecto al mando de José María Morelos, y emprender acciones represivas al iniciar el año de 1813, como fueron el encarcelamiento del periodista José Joaquín Fernández de Lizardi, la clausura del periódico El Pensador Mexicano, así como la persecución del escritor y político Carlos María Bustamante, quien durante el poco tiempo que duró la libertad de imprenta en Nueva España había editado el periódico El Juguetillo. Bustamante, incluso, fue uno de los electores del Ayuntamiento de México, no obstante, el clima represivo contra el pensamiento crítico, lo llevó a esconderse por un tiempo y después se pasó al bando de los insurgentes escribiendo en los periódicos Americano del Sur y el Semanario Patriótico Americano ${ }^{22}$.

El cambio de mando político en el virreinato a partir de la llegada de Feliz María Calleja, el 4 de marzo de 1813 -con tres cargos de manera indisoluble: gobernador militar, virrey y jefe superior-, también fue contraproducente para que prevaleciera el constitucionalismo gaditano en la Nueva España. De forma astuta, Calleja simuló ser una autoridad prudente pues, a un mes de su mandato, reanudó los comicios para elegir a los representantes del Ayuntamiento. No obstante, el calendario electoral fue elocuente: el 4 de abril de 1813 los electores eligieron ayuntamiento de México, dos alcaldes, dieciséis regidores y dos síndicos. Los días 4, 5 y 6 de julio duró el proceso de elección para diputados a cortes ordinarias en España y, supuestamente, para tenerse a los “jefes políticos" de las diecisiete juntas provinciales novohispanas. Los llamados Guadalupes -constituidos por un grupo de criollos con una postura política autonomista-, triunfaron nuevamente en las elecciones para los cabildos, diputaciones provinciales y a las Cortes $^{23}$. El resultado fue la elección de 18 diputados novohispanos -pero al no sufragarse los gastos para su traslado a Cádiz no asumieron el cargo-, y cuatro suplentes. Calleja, al considerar que la Nueva España era una provincia, los ciudadanos elegidos como "jefes políticos" pasarían entonces a ser diputados y conformarían solamente

21 MARCHENA, Juan: "La Constitución de Cádiz y el ocaso del sistema colonial...”, p.133.

22 VIZCAINO GUERRA, Fernando: Nación y nacionalismo en las Cortes de Cádiz. México, Instituto Investigaciones Sociales-UNAM, 2010, p. 94.

23 Véase al respecto el libro de Ernesto de la TORRE VILLAR: Los Guadalupes y la independencia, México, Editorial Jus, 1966. 
una junta provincial o "junta central" de $\mathrm{México}^{24}$. Si bien es cierto que estos últimos llegaron a la ciudad de México hasta el 13 de julio de 1814, sobra decir que solamente estuvieron en funciones por dos meses dado que, en septiembre del mismo año, se abolió la Constitución Política de la Monarquía Española.

Calleja, como Jefe Superior/Virrey, ante la penuria del erario y los gastos para enfrentar a las fuerzas emancipadoras encabezadas por Morelos, también impuso contribuciones, dispuso unilateralmente de los fondos públicos y recurrió a los préstamos de la Iglesia y de particulares adinerados. La mano dura de Calleja se hizo sentir en un bando del 13 de noviembre de 1814 que se desprendía de la observancia de la Ley de Indias para darle mayores facultades extraordinarias. Como advierte Christon Archer, estos fueron tiempos en que los comandantes realistas implementaron un abierto terrorismo con ejecuciones sumarias; presentando a hombres colgados en la entrada de los pueblos, ejerciendo la separación forzosa de la población que estaba con la causa insurgente y ordenando también la quema de poblados ${ }^{25}$.

Ya disueltas las Cortes y la derogada la Constitución, llegó el desquiciamiento del pretendido orden constitucional. Todo inició el 4 de mayo de 1814 cuando, a su regreso a España, el rey Fernando VII firmó un decreto en donde anulaba la Constitución de Cádiz, así como las leyes que se habían emitido durante su presencia en Francia ${ }^{26}$. La fidelidad al monarca español en Nueva España no se hizo esperar, y menos aún la represión contra aquellos diputados novohispanos más beligerantes. En este sentido, es conocida la actuación entreguista que tuvo el diputado por Puebla, Antonio Joaquín Pérez Martínez. Su sumisión como presidente de las Cortes todavía en mayo de 1814, fue fundamental para que de inmediato se acatara fielmente la orden del real decreto para que desaparecieran las mismas y hacer a un lado la Constitución de Cádiz ${ }^{27}$. La actuación servil de este personaje -que al poco tiempo fue recompensada al nombrársele obispo de Puebla- llegó cuando se adhirió al grupo absolutista llamado de los "persas" y delató a diputados novohispanos de la Cortes Constituyentes como Canga Argüelles, Villanueva y Gutiérrez de Terán para que pasaran al destierro, y a que José Miguel Ramos Arizpe estuviese por un tiempo en prisión en la Cartuja de Arachristi en Valencia y someterse a un juicio de Estado ${ }^{28}$.

Si bien, en Nueva España hubo un festín para la jura de la Constitución de Cádiz en octubre de 1812, con el retorno del antiguo régimen absolutista también hubo regocijo. El primer acto de entusiasmo se hizo en la ciudad de México cuando se supo, el 13 de junio de 1814, de la salida de Fernando VII de la frontera de Francia. La trascendencia de la noticia se concretó a partir de distintos cortejos para conmemorar dicho aconte-

24 GUEDEA, Virginia: "Las primeras elecciones populares en la ciudad de México, 1812-1813”, en Mexican Studies/Estudios Mexicanos, University of California Press, vol. VII, nº 1 (invierno 1991), pp. 1-28.

25 ARCHER, Christon: "La Revolución militar de México: estrategia, tácticas y logísticas durante la guerra de Independencia 1810-1821" en Josefina Vázquez (coord.): Interpretaciones de la Independencia, México, Nueva Imagen, 1997, p. 157.

$26 \mathrm{El}$ contenido del documento que retrotraía la realidad vivida con la ausencia del monarca es por si mismo nítido. El rey coloquialmente para deshacer el orden constitucional liberal escribió simplemente lo siguiente: "...como si no hubiesen pasado jamás tales actos, y se quitasen de en medio del tiempo".

27 En una carta de Antonio Joaquín Pérez fechada en Madrid el 11 de mayo de 1814 dirigida al capitán general de Castilla la Nueva decía: “...no solamente me abstendré de reunir en adelante a las Cortes, sino que doy por fenecidas desde este momento, así mis funciones como presidente, como mi calidad de diputado en un Congreso que ya no existe".

28 RAMOS ARIZPE, Miguel: Diccionario Porrua, historia, biografía y geografía de México, 1971, p. 1724. 
cimiento y el fandango se organizó entre los días 13 y 16 de junio del mismo año. Se hicieron iluminaciones, serenatas y corridas de toros. El festejo terminó, como se acostumbraba en ese entonces, con una solemne misa en la Iglesia de San Francisco ${ }^{29}$.

Sin embargo, todavía faltaba lo más dramático de la situación debido a que no fue, hasta los primeros días de agosto de 1814, cuando en Nueva España se supo ya con toda certeza, el desconocimiento de Fernando VII por la Constitución jurada en Cádiz. En consecuencia, Calleja se vistió nuevamente con el traje de virrey de Nueva España. Para el día 17 agosto a partir de un bando, este gobernante le advertía a la burocracia virreinal que se quitara a todo documento público o privado la denominación constitucional y a cambio se le incorporara el caduco lenguaje real y que, de inmediato, se restableciesen las corporaciones y juzgados del antiguo régimen absolutista español. Rápidamente, se empezaron a quitar las placas en las principales plazas públicas novohispanas que tuviesen la denominación Plaza de la Constitución y que, de inmediato, se renombraran simplemente como plazas mayores. Eso sucedió en las ciudades de México y Mérida y, aunque no se hizo de inmediato en la de Veracruz, al poco tiempo desapareció la inscripción que advertía la presencia de un régimen constitucional en el principal puerto novohispano. Y no obstante que hubo descontento del regreso al antiguo régimen entre algunos comerciantes españoles de los consulados de México y Veracruz simpatizantes de los principios liberales de la constitución gaditana, estos adinerados al poco tiempo guardaron sus reservas. De esta forma, se restablecía el ordenamiento borbónico-político que operaba antes de 1808 a través del Consejo de Castilla para la península y, para controlar las posesiones de ultramar, se restableció el Consejo de Indias. En consecuencia, fueron abolidos los juzgados de letras. Se le dio cabida nuevamente a los corregimientos y subdelegados y a la Repúblicas de los indios. Se restablecieron las audiencias de México y Guadalajara. El tribunal de la Inquisición reinició sus siniestras actividades a partir del 30 de diciembre de 1814 con el regreso de la horca, o bien, los castigos con azotes en la picota y en burro ${ }^{30}$. Volvieron los ministros de esos tribunales al goce de privilegios y sus comisiones.

Así, aquel proceso trascendente que se vivió en Nueva España durante la permanencia de la Constitución gaditana, como fue la propia elección de los ayuntamientos constitucionales novohispanos entre 1812 y 1814, se suspendió radicalmente de tajo. Para sustituir los cabildos elegidos por distintos sectores de la sociedad novohispana, se recurrió nuevamente a los "antiguos e ilustres ayuntamientos perpetuos". Primero fue disuelto el de la ciudad de México el 16 de diciembre de 1814 y luego, en un bando emitido el 20 de julio de 1815 , se cesaba a todos aquellos ayuntamientos constitucionales establecidos en Nueva España.

Con todo esto terminaba así la propuesta autonomista y liberal que si aceptaba una monarquía constitucional. En tanto, los realistas se dividieron en dos bandos y la Iglesia aprovechó la ocasión en busca del poder que había perdido en el intento que se dio para establecer un renovado régimen constitucional. Así, el nuevo régimen basado en sistema liberal y anhelado vehemente por el imaginario criollo novohispano e hispanoamericano cerraba su primer capítulo de la historia después de la caída del liberalismo gaditano.

29 Véase: Alfredo ZARATE: México a través de los siglos, libro segundo, capítulo XII, México, Editorial Cumbre, 1984, pp. 56-67.

30 Ibídem, pp. 66-67. 